\title{
Transcriptional profiling of myotubes from patients with type 2 diabetes: no evidence for a primary defect in oxidative phosphorylation genes
}

\author{
C. M. Frederiksen • K. Højlund $\cdot$ L. Hansen • \\ E. J. Oakeley • B. Hemmings • B. M. Abdallah • \\ K. Brusgaard $\cdot$ H. Beck-Nielsen $\cdot$ M. Gaster
}

Received: 24 April 2008 / Accepted: 7 July 2008 / Published online: 22 August 2008

(C) Springer-Verlag 2008

\begin{abstract}
Aims/hypothesis Microarray-based studies of skeletal muscle from patients with type 2 diabetes and high-risk individuals have demonstrated that insulin resistance and reduced mitochondrial biogenesis co-exist early in the pathogenesis of type 2 diabetes independently of hyperglycaemia and obesity. It is unknown whether reduced mitochondrial biogenesis or other transcriptional alterations co-exist with impaired insulin responsiveness in primary human muscle cells from patients with type 2 diabetes.
\end{abstract}

C. M. Frederiksen $\cdot$ K. Højlund $(\square) \cdot$ H. Beck-Nielsen •

M. Gaster

Diabetes Research Centre, Department of Endocrinology,

Odense University Hospital,

Kløvervænget 6,

5000 Odense C, Denmark

e-mail: k.hojlund@dadlnet.dk

L. Hansen

Steno Diabetes Center,

Gentofte, Denmark

E. J. Oakeley $\cdot$ B. Hemmings

Friedrich Miescher Institute for Biomedical Research,

Basel, Switzerland

B. M. Abdallah

Molecular Endocrinology Laboratory (KMEB),

Department of Endocrinology, Odense University Hospital,

Odense, Denmark

B. M. Abdallah

Medical Biotechnology Centre, University of Southern Denmark,

Odense, Denmark

K. Brusgaard

Department of Biochemistry, Pharmacology and Genetics,

Odense University Hospital,

Odense, Denmark
Methods Using cDNA microarray technology and global pathway analysis with the Gene Map Annotator and Pathway Profiler (GenMapp 2.1) and Gene Set Enrichment Analysis (GSEA 2.0.1), we examined transcript levels in myotubes established from obese patients with type 2 diabetes and matched obese healthy participants, who had been extensively metabolically characterised both in vivo and in vitro. We have previously reported reduced basal lipid oxidation and impaired insulin-stimulated glycogen synthesis and glucose oxidation in these diabetic myotubes. Results No single gene was differently expressed after correction for multiple testing, and no biological pathway was differently expressed using either method of global pathway analysis. In particular, we found no evidence for differential expression of genes involved in mitochondrial oxidative metabolism. Consistently, there was no difference in mRNA levels of genes known to mediate the transcriptional control of mitochondrial biogenesis (PPARGC1A and $N R F 1)$ or in mitochondrial mass between diabetic and control myotubes.

Conclusions/interpretation These results support the hypothesis that impaired mitochondrial biogenesis is not a primary defect in the sequence of events leading to insulin resistance and type 2 diabetes.

Keywords Cell culture - Genetics · Oxidative phosphorylation $\cdot$ Microarray $\cdot$ Skeletal muscle . Type 2 diabetes

\begin{tabular}{ll}
\multicolumn{2}{l}{ Abbreviations } \\
FDR & false discovery rate \\
FWER & familywise error rate \\
GenMAPP & Gene Map Annotator and Pathway Profiler \\
GSEA & Gene Set Enrichment Analysis
\end{tabular}


NRF1 nuclear respiratory factor 1

OXPHOS oxidative phosphorylation

PGC- $1 \alpha \quad$ peroxisome proliferator-activated receptor $\gamma$ coactivator $1 \alpha$

\section{Introduction}

Insulin resistance in skeletal muscle is a hallmark of type 2 diabetes and is characterised by increased intramyocellular lipid content, and several abnormalities in the biological response to insulin, including decreased glucose transport, glucose oxidation and glycogen synthesis [1-4]. Based on twin studies and epidemiological evidence, it is generally accepted that both genetic and environmental factors contribute to insulin resistance and subsequent development of type 2 diabetes [5]. This is supported by studies showing impaired insulin-stimulated glucose uptake and glycogen synthesis in glucose-tolerant first-degree relatives of patients with type 2 diabetes [6] and in primary human muscle cells (myotubes) from patients with type 2 diabetes [7-9]. Consistently, impaired insulin activation of phosphatidylinositol 3-kinase and glycogen synthase has been demonstrated in muscle of patients with type 2 diabetes $[2,10]$, their first-degree relatives [6] and diabetic myotubes $[7,8,11,12]$. It is still uncertain whether most of the abnormalities observed in vivo represent adaptive responses at the cellular level or are the consequences of a genetic defect. Hence, the primary molecular mechanisms underlying insulin resistance in human skeletal muscle remain largely unknown.

There is increasing evidence for a link between insulin resistance and impaired mitochondrial oxidative phosphorylation (OXPHOS) in human skeletal muscle in vivo. Most studies suggest that mitochondrial dysfunction in type 2 diabetes is primarily due to a lower content of muscle mitochondria [13, 14], whereas a role for decreased functional capacity per mitochondrion needs to be further explored [15-17]. Consistently, several microarray-based studies of skeletal muscle have reported coordinated downregulation of OXPHOS genes (mitochondrial biogenesis) in patients with type 2 diabetes and high-risk individuals [18-21], and that reduced expression of the genes encoding transcriptional coactivator peroxisome proliferator-activated receptor $\gamma$ coactivator $1 \alpha(\mathrm{PGC}-1 \alpha)$ and nuclear respiratory factor 1 (NRF1) could play a key role in these transcriptional changes [19-21]. Studies using magnetic resonance spectroscopy have shown lower rates of mitochondrial ATP production and substrate oxidation in lean, severely insulin-resistant first-degree relatives of patients with type 2 diabetes [22-23]. Thus, mitochondrial dysfunction and insulin resistance co-exist at an early point in the development of type 2 diabetes. However, it is clear that both insulin resistance and mitochondrial dysfunction in skeletal muscle are highly influenced by hyperglycaemia, physical activity, ageing, obesity and fibre type composition $[13,14,17,18,24,25]$. Thus, it is difficult to determine the extent to which these abnormalities are primary or secondary to environmental factors and metabolic changes associated with diabetes and prediabetic states.

Cultured human myotubes display the morphological, metabolic and biochemical properties of adult skeletal muscle [26] and offer a unique model to distinguish between genetic and environmental factors in the aetiology of insulin resistance and type 2 diabetes. We and others have reported a number of potential intrinsic defects in myotubes established from patients with type 2 diabetes, including lower basal palmitate oxidation and impaired insulin-stimulated glycogen synthesis and glucose oxidation [9, 27]. Whether these abnormalities co-exist with impaired mitochondrial biogenesis in diabetic myotubes is at present unknown.

To identify potential changes in the transcriptional profile associated with impaired insulin-responsiveness in diabetic myotubes, we compared microarray data from myotubes established and harvested under normoglycaemic and normoinsulinaemic conditions from a cohort of obese patients with type 2 diabetes and obese non-diabetic participants who had been extensively metabolically characterised in vivo and in vitro.

\section{Methods}

Materials DMEM, FCS, penicillin-streptomycin-amphotericin B and trypsin were obtained from Life Technologies (Paisley, UK). Ultroser G was purchased from Pall Biosepra (Cergy-Saint-Christophe, France). Uridine 5'-diphosphate$\left[{ }^{14} \mathrm{C}\right]$ glucose $\left(10.63 \mathrm{GBq} \mathrm{mol}^{-1}\right)$ was obtained from DuPont NEN (Boston, MA, USA). A protein assay kit was purchased from Bio-Rad (Copenhagen, Denmark). Glycogen, pepstatin, leupeptin, phenylmethylsulfonyl fluoride and ECM gel were purchased from Sigma Chemical (St Louis, MO, USA). Insulin Actrapid was from Novo Nordisk (Bagsvaerd, Denmark).

Study participants Ten obese patients with type 2 diabetes and ten healthy control participants, matched according to age and BMI, participated in the study (Table 1). Only sedentary male participants were recruited. Patients with type 2 diabetes were either treated by diet alone or diet in combination with sulfonylurea or metformin, which were withdrawn 1 week prior to the study. The patients were all negative for glutamic acid decarboxylase antibody and 
Table 1 In vivo and in vitro characteristics

\begin{tabular}{|c|c|c|}
\hline Characteristic & Control participants $(n=10)$ & Diabetic participants $(n=10)$ \\
\hline \multicolumn{3}{|l|}{ In vivo characteristics } \\
\hline Age (years) & $51.1 \pm 2.0$ & $50.4 \pm 1.6$ \\
\hline BMI $\left(\mathrm{kg} \mathrm{m}^{-2}\right)$ & $29.6 \pm 0.9$ & $31.1 \pm 1.1$ \\
\hline $\mathrm{HbA}_{1 \mathrm{c}}(\%)$ & $5.1 \pm 0.1$ & $6.9 \pm 0.5^{* *}$ \\
\hline Fasting plasma triacylglycerol $\left(\mathrm{mmol} \mathrm{l}^{-1}\right)$ & $1.4 \pm 0.2$ & $3.4 \pm 0.8^{*}$ \\
\hline Fasting plasma glucose $\left(\mathrm{mmol} \mathrm{l}^{-1}\right)$ & $5.5 \pm 0.1$ & $10.3 \pm 1.1^{* *}$ \\
\hline Fasting serum insulin $\left(\mathrm{pmol} \mathrm{l}^{-1}\right)$ & $40 \pm 5$ & $69 \pm 9^{*}$ \\
\hline Fasting serum NEFA $\left(\mathrm{mmol} \mathrm{l}^{-1}\right)$ & $0.49 \pm 0.06$ & $0.47 \pm 0.05$ \\
\hline Glucose disposal rate, basal $\left(\mathrm{mmol} \min ^{-1} \mathrm{~m}^{-2}\right)$ & $0.41 \pm 0.02$ & $0.49 \pm 0.02$ \\
\hline 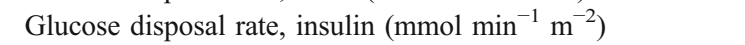 & $1.61 \pm 0.14$ & $1.00 \pm 0.15^{* *}$ \\
\hline Glucose oxidation, basal $\left(\mathrm{mmol} \min ^{-1} \mathrm{~m}^{-2}\right)^{\mathrm{a}}$ & $0.24 \pm 0.02$ & $0.29 \pm 0.05$ \\
\hline Glucose oxidation, insulin $\left(\mathrm{mmol} \min ^{-1} \mathrm{~m}^{-2}\right)^{\mathrm{a}}$ & $0.58 \pm 0.02$ & $0.43 \pm 0.05^{*}$ \\
\hline Lipid oxidation, basal $\left(\mathrm{nmol} \min ^{-1} \mathrm{~m}^{-2}\right)^{\mathrm{a}}$ & $56 \pm 2$ & $58 \pm 5$ \\
\hline Lipid oxidation, insulin $\left(\mathrm{nmol} \min ^{-1} \mathrm{~m}^{-2}\right)^{\mathrm{a}}$ & $27 \pm 3$ & $43 \pm 4 *$ \\
\hline Non-oxidative glucose disposal, basal $\left(\mathrm{mmol} \min ^{-1} \mathrm{~m}^{-2}\right)^{\mathrm{a}}$ & $0.15 \pm 0.02$ & $0.20 \pm 0.04$ \\
\hline Non-oxidative glucose disposal, insulin $\left(\mathrm{mmol} \min ^{-1} \mathrm{~m}^{-2}\right)^{\mathrm{a}}$ & $1.09 \pm 0.12$ & $0.66 \pm 0.13 *$ \\
\hline \multicolumn{3}{|l|}{ In vitro characteristics (myotubes) } \\
\hline Glucose oxidation, basal (pmol [mg protein $]^{-1} \min ^{-1}$ ) & $382 \pm 42$ & $429 \pm 41$ \\
\hline Glucose oxidation, insulin (pmol $[\mathrm{mg} \text { protein }]^{-1} \min ^{-1}$ ) & $531 \pm 46$ & $423 \pm 38^{*}$ \\
\hline Lipid oxidation, basal (pmol $[\mathrm{mg} \text { protein }]^{-1} \mathrm{~min}^{-1}$ ) & $24.4 \pm 1.5$ & $18.1 \pm 1.9^{*}$ \\
\hline Lipid oxidation, insulin (pmol [mg protein $]^{-1} \min ^{-1}$ ) & $24.5 \pm 2.4$ & $18.0 \pm 2.1^{*}$ \\
\hline Glycogen synthesis, basal (pmol [mg protein $]^{-1} \min ^{-1}$ ) & $68 \pm 12$ & $50 \pm 8$ \\
\hline Glycogen synthesis, insulin (pmol $[\mathrm{mg} \text { protein }]^{-1} \min ^{-1}$ ) & $141 \pm 22$ & $87 \pm 12 *$ \\
\hline
\end{tabular}

The table shows characteristics of type 2 diabetic and control participants in the basal and insulin-stimulated states as reported previously [2, 9 , 27]. Data are mean \pm SEM

${ }^{*} p<0.05$ and $* * p<0.01$ vs control

${ }^{a}$ Based on indirect calorimetry in eight control and nine diabetic participants

without signs of diabetic retinopathy, nephropathy, neuropathy or macrovascular complications. The control participants had normal glucose tolerance and no family history of diabetes. All participants had normal results of screening blood tests of hepatic and renal function. Informed consent was obtained from all participants before participation. The study was approved by the local ethics committee and was performed in accordance with the Declaration of Helsinki II.

In vivo characteristics Total glucose disposal rate and rates of glucose and lipid oxidation were assessed by euglycaemic-hyperinsulinaemic clamp studies (equilibration for $2 \mathrm{~h}$ followed by insulin infusion for $4 \mathrm{~h}, 40 \mathrm{mU} \mathrm{min}{ }^{-1} \mathrm{~m}^{-2}$ ) combined with indirect calorimetry as described in detail previously [2, 28]. Non-oxidative glucose disposal was calculated as the difference between the rates of total glucose disposal and glucose oxidation. Plasma glucose, serum insulin, NEFA and triacylglycerol were measured as described previously [29]. Skeletal muscle biopsies were obtained in the basal steady-state period of the clamp from the vastus lateralis muscle using a modified Bergström needle with suction under local anaesthesia.
Cell culture Cell cultures were established as described previously $[8,26]$. In brief, muscle tissue was minced, washed and dissociated for $60 \mathrm{~min}$ by three treatments with $0.05 \%$ trypsin-EDTA. The harvested cells were pooled and FCS was added to stop trypsinisation. The cells obtained were seeded for upscaling on ECM gel-coated dishes after $30 \mathrm{~min}$ of preplating. Cell cultures were established in DMEM medium supplemented with $10 \%$ FCS, $50 \mathrm{U} \mathrm{ml}^{-1}$ penicillin, $50 \mu \mathrm{g} \mathrm{ml}^{-1}$ streptomycin and $1.25 \mu \mathrm{g} \mathrm{ml}^{-1}$ amphotericin B. After $24 \mathrm{~h}$ cell debris and non-adherent cells were removed by change of growth medium to DMEM supplemented with $2 \%$ FCS, $2 \%$ Ultroser G, $50 \mathrm{U} \mathrm{ml}^{-1}$ penicillin, $50 \mu \mathrm{g} \mathrm{ml}^{-1}$ streptomycin and $1.25 \mu \mathrm{g} \mathrm{ml}^{-1}$ amphotericin B. Cells were subcultured twice before final seeding. At $75 \%$ confluence the growth medium was replaced by basal medium (DMEM supplemented with $2 \%$ FCS, $50 \mathrm{U} \mathrm{ml}^{-1}$ penicillin, $50 \mu \mathrm{g} \mathrm{ml}^{-1}$ streptomycin, $1.25 \mathrm{\mu g} \mathrm{ml}^{-1}$ amphotericin B and $25 \mathrm{pmol} \mathrm{l}^{-1}$ insulin) in order to induce differentiation. The cells were cultured in a humidified $5 \% \mathrm{CO}_{2}$ atmosphere at $37^{\circ} \mathrm{C}$, and medium was changed every 2-3 days. Human myotubes established from controls and participants with type 2 diabetes were allowed to differentiate under physiological 
conditions of insulin $\left(25 \mathrm{pmol} \mathrm{l}^{-1}\right)$ and glucose $(5.5 \mathrm{mmol}$ $1^{-1}$ ) for 8 days. All myotube cultures were used for analysis on day 8 after onset of differentiation.

In vitro characteristics Results of glycogen synthesis, glucose oxidation and lipid oxidation under basal and insulin-stimulated conditions in myotubes established from the diabetic and control participants included in this study have been reported previously $[9,27]$. In brief, differentiated myotubes were exposed to either radiolabelled palmitic acid $\left(0.6 \mathrm{mmol} \mathrm{l}^{-1}\right)$ or glucose $\left(5.5 \mathrm{mmol}^{-1}\right)$, and either $25 \mathrm{pmol}$ $1^{-1}$ (basal) or $1 \mu \mathrm{mol} 1^{-1}$ insulin in serum-free DMEM for $4 \mathrm{~h}$ $[9,27]$. Refer to these papers for further details.

Sample preparation Total RNA was prepared from muscle cell cultures using RNeasy (Qiagen, Hilden, Germany) and microarray analysis was performed using Human Genome U95Av2 GeneChips (Affymetrix, Santa Clara, CA, USA). Total RNA isolated from cultured human myotubes was reverse-transcribed using the SuperScript Choice system for cDNA synthesis (Life Technologies) according to the protocol recommended by Affymetrix (GeneChip Expression Analysis: Technical Manual [2001], p. 2.1.14-2.1.16). The sequence of the oligonucleotide used for priming was 5'-GGCCAGTGAATTGTAATACGACTCACTATAGG GAGGCGG-(T) $24-3^{\prime}$ (Genset Oligo, Paris, France) as recommended by Affymetrix. Double-stranded cDNA was cleaned by phenol-chloroform extraction and the aqueous phase was removed by centrifugation through Phase-lock Gel (Eppendorf, Hamburg, Germany). In vitro transcription was performed on $1 \mu \mathrm{g}$ of cDNA using the Enzo BioArray high-yield RNA transcript labelling kit (Enzo Diagnostics, Farmindale, NY, USA) following the manufacturer's protocol. The cRNA was cleaned using RNAeasy clean-up columns (Qiagen). To improve recovery from the columns, the elution water was spun into the matrix at $27 \mathrm{~g}$ and then left for $1 \mathrm{~min}$ prior to the standard 8,000 $\mathrm{g}$ centrifugation recommended by Qiagen. This low-speed wetting step gave us nearly double the yield of eluted RNA. The cRNA was fragmented by heating in $1 \times$ fragmentation buffer (40 mmol $\mathrm{l}^{-1}$ Tris-acetate, $\mathrm{pH} 8.1,100 \mathrm{mmol} \mathrm{l}^{-1} \mathrm{KOAc}$, $30 \mathrm{mmol}^{-1} \mathrm{MgOAc}$ ) as recommended by Affymetrix. Ten micrograms of fragmented cRNA was hybridised to a U95Av2 GeneChip (Affymetrix) using the manufacturer's standard procedure $\left(45^{\circ} \mathrm{C}, 16 \mathrm{~h}\right)$. Washing and staining were performed in a Fluidics Station 400 (Affymetrix) using the protocol EukGE-WS2v4 and scanned in an Affymetrix GeneChip 2500 scanner.

Data analysis Microarray normalisation and calculation of expression measures were performed using Robust Multiarray Average [30], implemented in the statistical package $\mathrm{R}$ provided by Bioconductor (Seattle, WA, USA) [31]. The expression values were $\log 2$ transformed to obtain a normal distribution across arrays and samples. Before analysing the expression data we removed Affymetrix control probes, resulting in a total of 12,558 probes.

Supervised analysis The Comparative Marker Selection suite in the GenePattern analysis environment (http://www.broad. mit.edu/genepattern) was used to find genes that could discriminate between diabetic and control myotubes. A total of 1,000 permutations were performed for the estimation of nominal $p$ values, which were then corrected for multiple hypothesis testing using the false discovery rate (FDR) and the familywise error rate (FWER). FDR $<0.01$ and FWER $<0.05$ were considered significant in our study.

Global pathway analysis Gene Set Enrichment Analysis (GSEA) and Gene Map Annotator Profiler (GenMAPP 2.1) were used to evaluate the contributions of gene pathways to the transcriptional differentiation of samples. In GSEA, all genes were ranked by signal-to-noise ratio. A total of 513 gene sets were applied using the gene set browser module (MSigDB) in the GSEA software. This included 456 gene sets defined by Curated (Collection), Generic (Organism), Gene symbol (CHIP) and contributed by Biocarta, GenMAPP, SIGNALING Transduction KE, SIGNALINGAlliance, SigmaAldrich, GO and GEArray (CONTRIBUTOR). In addition, 57 gene sets defined by Curated, Human, Gene symbol and contributed by the Broad Institute and Vamsi Mootha were included. An enrichment score was generated for each gene set, and statistical significance was estimated using phenotype-based permutations. In this analysis, 2,000 permutations were used to obtain the nominal $p$ values, and FDR $<0.25$ and FWER $<0.05$ was considered significant after correction for multiple hypothesis testing.

The MAPPFinder 2.1 tool in GenMAPP 2.1 was used to determine whether any gene sets or pathways were significantly up- or downregulated in the diabetic vs control myotubes. We used all contributed human pathways available in the MAPP archives. A fold change of $>1.05$ or $<-1.05$ and $p<0.05$ (unadjusted) were used as the criteria for gene expression changes between diabetic and control myotubes. The statistical rating of the relative gene expression activity was provided by the $z$ score. The $z$ score was based on the number of genes $(N)$ linked to local MAPPs and the number of these genes $(R)$ meeting the criteria for change in expression. A pathway with a $z$ score $>2.0$ was considered significantly regulated. A non-parametric statistic, based on 2,000 permutations, was applied to access the statistical significance of the $z$ score (permute P). To account for multiple hypothesis testing, the FWER was calculated for each pathway (www.GenMAPP.org). Under- 
scoring between words in the text and Tables 2 and 3 indicates names of gene sets in GenMAPP GSEA.

Total RNA isolation and RT-PCR analysis Total RNA was isolated from human myotubes using a single-step method with Trizol (Invitrogen, Tastrup, Denmark) according to the manufacturer's instructions. The integrity and purity of total RNA were verified spectrophotometrically and by gel electrophoresis on $0.8 \%$ SeaKem agarose (BMA, Hellerup, Denmark). cDNA was synthesised from $5 \mu \mathrm{g}$ of total RNA using a Revertaid H Minus First Strand cDNA Synthesis Kit (Fermentas, Copenhagen, Denmark) according to the manufacturer's instructions. RT-PCR was performed using the iCycler IQ detection system (Bio-Rad, Herlev, Denmark) by using SYBR Green I as a double-strand DNA-specific binding dye. Thermocycling was performed in a final volume of $20 \mu \mathrm{l}$ containing $3 \mu \mathrm{l}$ of cDNA sample (diluted 1:20), 20 pmol of each primer and $2 \times$ iQ SYBR Green Supermix (Bio-Rad). The following human specific primers were used: NRF1 forward, 5'-AACAAAATTGGGCCACGTTACA-3'; NRF1 reverse, 5'-TCTGGACCAGGCCATTAGCA-3'; PPARGC1A forward, 5'-GCTTTCTGGGTGGACTCAAGT-3'; PPARGC1A reverse, 5'-TCTAGTGTCTCTGTGAGGACTG-3'. Quantifications of each target gene and $\beta$-actin mRNA were performed in separate tubes. Gene expression levels for each target gene were calculated using the comparative
$\mathrm{C}_{\mathrm{t}}$ method formula $\left(1 /\left[2 \Delta \mathrm{C}_{\mathrm{t}}\right]\right)$, where $\Delta \mathrm{C}_{\mathrm{t}}$ is the difference between $C_{t}$ target and $C_{t}$ reference after normalisation to $\beta$-actin mRNA (PerkinElmer User Bulletin No. 2). Data were analysed using optical system software version 3.1 (Bio-Rad) and Microsoft Excel 2000 to generate relative expression values.

Mitochondrial mass For the quantification of mitochondrial mass, we used MitoTracker Green Probe (Molecular Probes, Eugene, OR, USA), which preferentially accumulates in mitochondria regardless of the mitochondrial membrane potential and gives an assessment of the mitochondrial mass. Myotubes were incubated at $37^{\circ} \mathrm{C}$ for 30 min with $200 \mathrm{nmol}^{-1}$ MitoTracker Green in DMEM and subsequently washed with PBS. Fluorescence intensity was determined on a Victor plate reader model 1420-050 (PerkinElmer, Turku, Finland) with excitation and emission wavelengths of 485 and $535 \mathrm{~nm}$, respectively. Values were corrected for protein and expressed as arbitrary units.

\section{Results}

In vivo and in vitro characteristics As reported previously [2], the diabetic patients had increased fasting levels of $\mathrm{HbA}_{1 \mathrm{c}}$, plasma glucose, serum insulin and plasma triacyl-

Table 2 The ten most up- and downregulated gene sets analysed with GSEA

\begin{tabular}{|c|c|c|c|c|c|c|}
\hline Name & Size & ES & NES & NOM $p$ value & FDR $q$ value & FWER $p$ value \\
\hline \multicolumn{7}{|l|}{ Downregulated in diabetic myotubes } \\
\hline Cholesterol_biosynthesis & 17 & -0.73 & -1.54 & 0.05 & 1.00 & 0.87 \\
\hline Rac1pathway & 38 & -0.48 & -1.49 & 0.03 & 1.00 & 0.96 \\
\hline Pitx2pathway & 21 & -0.57 & -1.47 & 0.07 & 1.00 & 0.97 \\
\hline Erk5pathway & 24 & -0.69 & -1.45 & 0.07 & 1.00 & 0.98 \\
\hline Inositol_phosphate_metabolism & 33 & -0.49 & -1.43 & 0.06 & 1.00 & 0.99 \\
\hline Calcium_regulation_in_cardiac_cells & 180 & -0.34 & -1.41 & 0.01 & 1.00 & 1.00 \\
\hline Ctla4pathway & 27 & -0.56 & -1.38 & 0.13 & 1.00 & 1.00 \\
\hline Mitochondrial_fatty_acid_oxidation & 15 & -0.57 & -1.37 & 0.11 & 1.00 & 1.00 \\
\hline P53hypoxiapathway & 38 & -0.50 & -1.37 & 0.06 & 1.00 & 1.00 \\
\hline Carm_Erpathway & 36 & -0.46 & -1.33 & 0.14 & 1.00 & 1.00 \\
\hline \multicolumn{7}{|l|}{ Upregulated in diabetic myotubes } \\
\hline Phenylalanine_metabolism & 22 & 0.71 & 1.84 & $<0.001$ & 0.12 & 0.08 \\
\hline Tyrosine_metabolism & 36 & 0.76 & 1.79 & $<0.001$ & 0.14 & 0.16 \\
\hline Prostaglandin_and_leukotriene_metabolism & 31 & 0.72 & 1.66 & $<0.01$ & 0.46 & 0.52 \\
\hline Electron_transporter_activity & 121 & 0.48 & 1.65 & $<0.01$ & 0.40 & 0.56 \\
\hline DNA_replication_reactome & 57 & 0.52 & 1.59 & 0.03 & 0.64 & 0.77 \\
\hline Glycerolipid_metabolism & 44 & 0.64 & 1.57 & 0.01 & 0.63 & 0.81 \\
\hline Eicosanoid_synthesis & 21 & 0.77 & 1.52 & 0.02 & 0.83 & 0.91 \\
\hline Tryptophan_metabolism & 72 & 0.44 & 1.52 & 0.02 & 0.78 & 0.93 \\
\hline St_interferon_gamma_pathway & 16 & 0.76 & 1.50 & 0.03 & 0.77 & 0.95 \\
\hline Butanoate_metabolism & 27 & 0.48 & 1.50 & $<0.01$ & 0.70 & 0.95 \\
\hline
\end{tabular}

All genes on the chip were ranked by difference in expression between diabetic and control myotubes using the $t$ test $\mathrm{ES}$, enrichment score; NES, enrichment score normalised for differences in gene set size; NOM, nominal 
glycerol, whereas plasma NEFA levels were similar (Table 1). The insulin-stimulated glucose disposal rate was 38\% lower in diabetic patients than in controls, and this was primarily accounted for by a $40 \%$ reduction in non-oxidative glucose disposal, but also by a $25 \%$ decrease in glucose oxidation. Moreover, the ability of insulin to suppress lipid oxidation during the clamp was significantly impaired in diabetic patients.

Myotubes established from diabetic and control participants were inspected visually under phase-contrast microscopy, and did not differ in appearance. As reported previously [9, 27], diabetic myotubes showed reduced insulin-mediated glucose oxidation (20\%) and glycogen synthesis (38\%), whereas lipid oxidation, measured as production of $\mathrm{CO}_{2}$ in response to palmitate exposure, was decreased by $26 \%$ under both basal and insulin-stimulated conditions (Table 1).

Quality control of microarrays To confirm the quality of the microarray data we made a box plot of the expression values after normalisation. The box plot showed that median expression values for all arrays were on the same level and were evenly distributed after normalisation.

Supervised analysis Using the Comparative Marker Selection suite in GenePattern, we observed that none of 12,558 probe sets could discriminate between diabetic and control myotubes when corrected for multiple hypothesis testing using either FDR $<0.01$ or FWER $<0.05$ (data not shown).

Global pathway analysis Using phenotype-based permutations on the 513 gene sets included in the GSEA analysis, no pathways were downregulated, whereas two gene sets, phenylalanine_metabolism and tyrosine_metabolism, were upregulated in diabetic vs control myotubes using FDR $<0.25$ as the criterion. However, when applying the more stringent FWER $<0.05$ as the criterion, no gene sets were differently regulated between diabetic and control myotubes (Table 2). The gene sets electron_transport_chain, oxidative_phosphorylation, and Mootha_voxphos, were not differentially regulated (all FDR $>0 . \overline{9}$, and FWER=1.00).

Table 3 The ten most up- and downregulated gene sets analysed with MAPPFinder

\begin{tabular}{|c|c|c|c|c|c|c|c|}
\hline MAPP name & $\begin{array}{l}\text { Changed } \\
(n)^{\mathrm{a}}\end{array}$ & $\begin{array}{l}\text { Measured } \\
(n)^{\mathrm{b}}\end{array}$ & $\begin{array}{l}\text { On MAPP } \\
(n)^{\mathrm{c}}\end{array}$ & $\begin{array}{l}\text { Changed } \\
(\%)^{\mathrm{d}}\end{array}$ & $z$ score & $\begin{array}{l}\text { Permuted } \\
p \text { value }\end{array}$ & $\begin{array}{l}\text { FWER } \\
p \text { value }\end{array}$ \\
\hline \multicolumn{8}{|l|}{ Downregulated in diabetic myotubes } \\
\hline Integrin-mediated_cell_adhesion & 7 & 87 & 99 & 8.0 & 2.9 & $<0.01$ & 0.59 \\
\hline Fatty_acid_omega_oxidation & 2 & 15 & 15 & 13.3 & 2.4 & 0.08 & 0.87 \\
\hline Focal_adhesion & 10 & 169 & 187 & 5.9 & 2.4 & 0.02 & 0.87 \\
\hline Nucleotide_metabolism & 2 & 16 & 17 & 12.5 & 2.3 & 0.08 & 0.91 \\
\hline Pentose_phosphate_pathway & 1 & 5 & 7 & 20.0 & 2.3 & 0.15 & 0.94 \\
\hline RNA_transcription_reactome & 3 & 32 & 40 & 9.4 & 2.2 & 0.05 & 0.95 \\
\hline Nuclear_receptors_in_lipid_metabolism_and_toxicity & 3 & 32 & 33 & 9.4 & 2.2 & 0.05 & 0.95 \\
\hline S1P_signaling & 2 & 20 & 25 & 10.0 & 1.9 & 0.12 & 0.99 \\
\hline Heme_biosynthesis & 1 & 9 & 9 & 11.1 & 1.5 & 0.24 & 1.00 \\
\hline MAPK_signaling_pathway & 7 & 145 & 162 & 4.8 & 1.4 & 0.21 & 1.00 \\
\hline \multicolumn{8}{|l|}{ Upregulated in diabetic myotubes } \\
\hline Smooth_muscle_contraction & 11 & 138 & 156 & 8.0 & 3.3 & $<0.001$ & 0.41 \\
\hline Triacylglyceride_synthesis & 3 & 18 & 24 & 16.7 & 3.3 & 0.02 & 0.44 \\
\hline Irinotecan_pathway & 2 & 12 & 12 & 16.7 & 2.7 & 0.06 & 0.73 \\
\hline Oxidative_stress & 3 & 24 & 28 & 12.5 & 2.6 & 0.03 & 0.74 \\
\hline Calcium_regulation_in_cardiac_cells & 9 & 127 & 149 & 7.1 & 2.6 & 0.01 & 0.74 \\
\hline Fatty_acid_omega_oxidation & 2 & 15 & 15 & 13.3 & 2.3 & 0.08 & 0.90 \\
\hline Biogenic_amine_synthesis & 2 & 15 & 15 & 13.3 & 2.3 & 0.08 & 0.90 \\
\hline Prostaglandin_synthesis_regulation & 3 & 30 & 31 & 10.0 & 2.2 & 0.07 & 0.91 \\
\hline Synthesis_and_degradation_of_ketone_bodies & 1 & 5 & 5 & 20.0 & 2.2 & 0.17 & 0.94 \\
\hline Small ligand GPCRs & 2 & 17 & 18 & 11.8 & 2.0 & 0.10 & 0.97 \\
\hline
\end{tabular}

A fold change $>1.05$ or less than -1.05 and a $p$ value $<0.05$ (unadjusted) were used as the criteria for gene expression changes between diabetic and control myotubes. Among the 2,544 genes linked to local MAPPS, $R=74$ and $R=80$ genes met the criteria for up- and downregulation, respectively (see "Methods")

${ }^{\mathrm{a}}$ Number of genes changed

${ }^{\mathrm{b}}$ Number of genes measured on the chip

${ }^{\mathrm{c}}$ Number of genes on the MAPP

${ }^{\mathrm{d}}$ Number changed divided by number measured 
Using the MAPPFinder tool in GenMAPP on human pathways, significant $z$ scores (FDR $<0.01$ ) were observed for downregulation of integrin_mediated_cell_adhesion and upregulation of smooth_muscle_contraction in diabetic vs control myotubes. However, when controlling for multiple hypothesis testing using FWER $<0.05$, no pathways were significantly regulated (Table 3 ). The Electron_transport chain showed FDR $>0.38$ and FWER $=1.00$ in both analyses. In fact, only one of the 85 genes measured met the criteria for up- and downregulation, respectively.

Evaluating the results from both GSEA and GenMAPP, there were no pathways that were consistently down- or upregulated in diabetic vs control myotubes. In both analyses, we found no evidence for differential regulation of the pathways representing OXPHOS.

$R T-P C R$ and mitochondrial mass To validate our results, we examined gene expression of PPARGC1A and NRF1, which are known to be involved in the transcriptional control of mitochondrial biogenesis. There was no difference in mRNA levels of PGC-1 $\alpha(p=0.89)$ or NRF1 ( $p=$ 0.26 ) between diabetic and control myotubes (Fig. 1a, b). Moreover, in a subset of the diabetic $(n=5)$ and control myotubes $(n=6)$, we could not detect any difference in mitochondrial mass $(p=0.32)$ (Fig. 1c).

\section{Discussion}

Cultured human myotubes represent a well-characterised in vitro model system of skeletal muscle in which the extracellular environment can be controlled precisely and kept constant over time [26]. In the present study, we took advantage of this model to compare the transcript levels of muscle genes required for basal homeostasis in myotubes established from obese patients with type 2 diabetes and matched healthy control participants. As in studies of muscle transcript levels in patients with type 2 diabetes in vivo [18-20], we could not find any single gene that was significantly regulated after correction for multiple hypothesis testing in diabetic myotubes. To search for gene sets enriched in diabetic vs control myotubes, we used two different methods for global pathway analysis, GenMAPP and GSEA, which are well-established tools used to identify novel biological pathways of interest in the pathogenesis of complex disorders such as insulin resistance [19-21]. In contrast to recent in vivo studies [18-20], we could not find evidence for differential gene expression in any biological pathways in diabetic vs control myotubes, and, in particular, genes and pathways representing mitochondrial OXPHOS displayed almost no variability. Consistently, we observed no difference in mRNA levels of $P G C-1 \alpha$ and NRF1, which are known to mediate the a

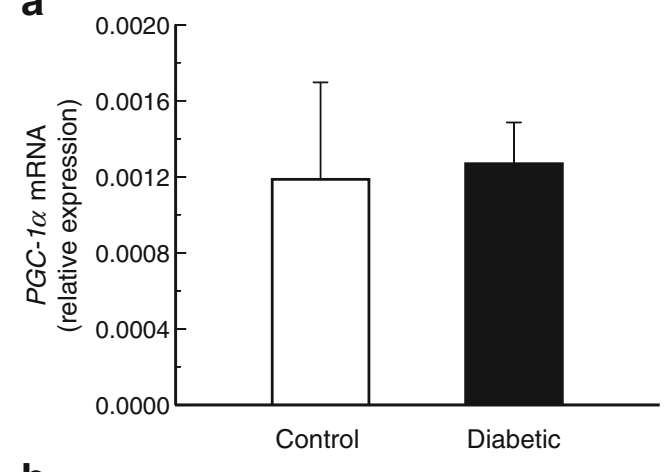

b
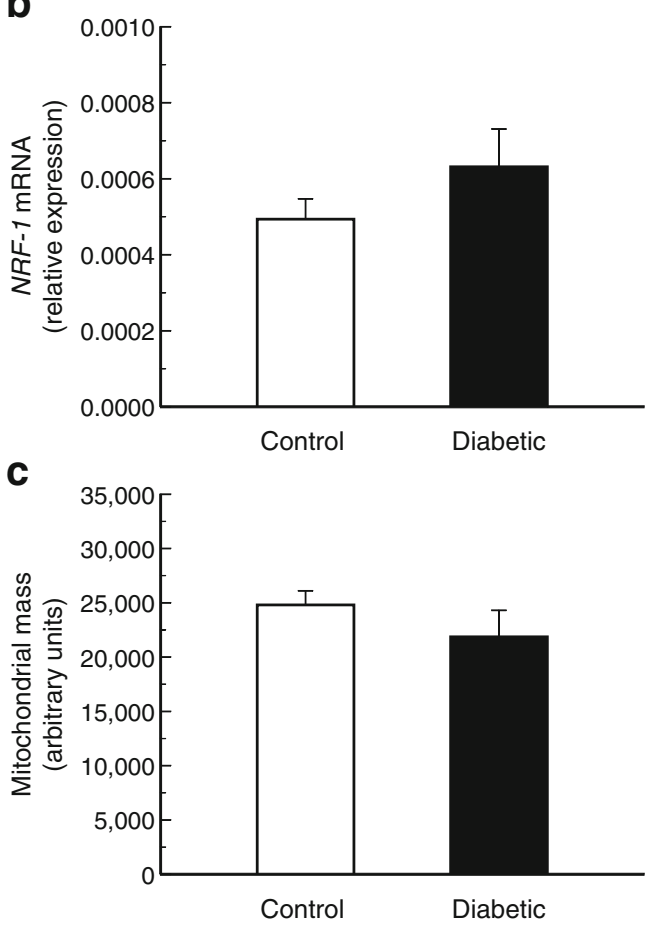

Fig. 1 PPARGC1A (translated into PGC-1 $\alpha$ ) (a) and NRF1 (b) mRNA levels determined by quantitative real-time PCR in myotubes established from control participants $(n=10)$ and patients with type 2 diabetes $(n=10)$, expressed relative to $\beta$-actin. $\mathbf{c}$ Mitochondrial mass was determined by MitoTracker Green fluorescence in myotubes from a subset of the control $(n=6)$ and diabetic participants $(n=5)$. All data are mean \pm SEM. There were no significant differences between control and diabetic participants

transcriptional control of mitochondrial biogenesis, or in mitochondrial mass between diabetic and control myotubes. These data indicate that under basal conditions there are no intrinsic (inborn) errors in the factors controlling transcriptional regulation and mitochondrial biogenesis in diabetic muscle.

A number of studies have provided support for the hypothesis of a link between mitochondrial dysfunction and insulin resistance in human skeletal muscle [13-24, 32], and that these abnormalities co-exist at an early point in the development of type 2 diabetes [21-23]. The lack of 
transcriptional alterations in diabetic myotubes in our study, however, suggests that the downregulation of mitochondrial OXPHOS genes observed in insulin-resistant skeletal muscle in vivo is caused by differences in the magnitude of or response to factors outside the muscle cell, such as neuronal regulation, blood flow and circulating levels of substrates, cytokines and hormones. This idea is supported by several recent studies, which have indicated that both absolute and relative insulinopenia (insulin resistance), hyperglycaemia and circulating levels of NEFA are possible factors contributing to impaired mitochondrial biogenesis in vivo [14, 17, 18, 32-34]. Accordingly, none of the present human studies have been able to prove a cause-and-effect relationship between mitochondrial dysfunction and insulin resistance in vivo [13-24]. Further studies in human myotubes are warranted to study the effects of these factors separately, e.g. whether an abnormal transcriptional response to palmitate exposure could contribute to the impaired lipid oxidation observed in diabetic myotubes [27].

In vivo, skeletal muscle takes up and stores the most of the glucose during insulin stimulation, and the response to this hormonal factor is reduced in patients with type 2 diabetes [2]. This insulin-resistant phenotype can also be found in diabetic myotubes [7-9], indicating that at least insulin resistance could be a primary defect. It is likely that the maintenance of mitochondria in vivo involves a normal adaptation to the repeated bursts of physiological hyperinsulinaemia elicited by food intake. Recent microarraybased studies of skeletal muscle from healthy humans have shown that most genes upregulated in response to acute insulin infusion are involved in transcriptional and translational regulation as well as a number of genes involved in mitochondrial processes such as lipid oxidation, the citric acid cycle and OXPHOS [35-36]. Hence, an intrinsic defect in the adaptation to insulin in muscle may affect gene transcription and mitochondrial biogenesis. In support of this idea, the ability of insulin to stimulate ATP production and OXPHOS gene expression in skeletal muscle is impaired in patients with type 2 diabetes and their firstdegree relatives [37-39]. Our study cannot exclude the possibility that a primary defect in insulin action on the muscle cell causes mitochondrial dysfunction, and that if myotubes were studied under conditions similar to those observed in vivo we would find reduced mitochondrial biogenesis. On the other hand, it is known that muscle cells in culture are quite different from skeletal muscle regarding their oxidative capacities, mitochondrial content and subcellular distribution of mitochondria. We have shown previously that insulin may regulate different pools of genes in skeletal muscle in vivo and cultured muscle cells in vitro [40-41]. Using diabetic and control myotubes stimulated with supraphysiological insulin levels $\left(1 \mu \mathrm{mol} \mathrm{l}^{-1}\right)$, none of the
144 genes that responded differentially to insulin in diabetic vs control myotubes were OXPHOS genes [41]. These data argue against impaired insulin-mediated transcriptional regulation of OXPHOS genes in diabetic myotubes.

In another study from our group, we found no difference in maximal ADP-stimulated respiration between myotubes established from lean, obese and type 2 diabetic participants [42]. Together with the lack of abnormalities in mRNA levels of $P G C-1 \alpha$ and $N R F 1$ and mitochondrial mass in the present study, these data indicate that an insulin-resistant phenotype is present in a human muscle cell model of type 2 diabetes without alterations in the transcriptional levels of OXPHOS genes, mitochondrial content and function. Although most studies of human skeletal muscle in vivo have reported the co-existence of impaired insulin sensitivity and reduced expression of OXPHOS genes and mitochondrial content/function [13-24], there is so far no clear evidence for a mechanistic link or even strong correlation between these parameters. In fact, two recent studies have provided evidence for disassociation between mitochondrial dysfunction and insulin resistance in skeletal muscle of mice and humans [43, 44].

In summary, we tested the hypothesis that alterations in the transcriptional profile contribute to the diabetic phenotype of myotubes established from patients with type 2 diabetes. Despite clear defects in insulin-stimulated glucose metabolism both in vivo and in vitro, and an impaired ability to oxidise lipids during palmitate exposure in vitro, we did not demonstrate the existence of differential transcript levels of muscle genes between diabetic and control myotubes. In particular, there were no changes in genes and pathways representing the mitochondrial OXPHOS. This is in contrast to most in vivo data, and indicates that, at least under basal conditions, no major primary defect in gene transcription or mitochondrial biogenesis precedes or co-exists with the abnormalities in insulin-stimulated glucose metabolism.

Acknowledgements We thank Herbert Angliker and Irene Lynfort for excellent technical assistance. The Danish Medical Research council and the Novo-Nordisk Foundation are thanked for financial support.

Duality of interest The authors declare that there is no duality of interest associated with this manuscript.

\section{References}

1. Højlund K, Beck-Nielsen H (2006) Impaired glycogen synthase activity and mitochondrial dysfunction in skeletal muscle. Markers or mediators of insulin resistance in type 2 diabetes. Curr Diabetes Rev 2:375-395

2. Højlund K, Staehr P, Hansen BF et al (2003) Increased phosphorylation of skeletal muscle glycogen synthase at $\mathrm{NH} 2$ terminal sites during physiological hyperinsulinemia in type 2 diabetes. Diabetes 52:1393-1402 
3. Gaster M, Ottosen PD, Vach W et al (2003) GLUT4 expression in human muscle fibres is not correlated with intracellular triglyceride (TG) content. Is TG a maker or a marker of insulin resistance. APMIS 111:338-348

4. Levin K, Daa Schroeder H, Alford FP et al (2001) Morphometric documentation of abnormal intramyocellular fat storage and reduced glycogen in obese patients with type II diabetes. Diabetologia 44:824-833

5. Beck-Nielsen H, Vaag A, Poulsen P et al (2003) Metabolic and genetic influence on glucose metabolism in type 2 diabetic subjects - experiences from relatives and twin studies. Best Pract Res Clin Endocrinol Metab 17:445-467

6. Vaag A, Henriksen JE, Beck-Nielsen H (1992) Decreased insulin activation of glycogen synthase in skeletal muscles in young nonobese Caucasian first-degree relatives of patients with noninsulin-dependent diabetes mellitus. J Clin Invest 89:782-788

7. Henry RR, Ciaraldi TP, Abrams-Carter L, Mudaliar S, Park KS, Nikoulina SE (1996) Glycogen synthase activity is reduced in cultured skeletal muscle cells of non-insulin-dependent diabetes mellitus subjects. Biochemical and molecular mechanisms. J Clin Invest 98:1231-1236

8. Gaster M, Petersen I, Højlund K, Poulsen P, Beck-Nielsen H (2002) The diabetic phenotype is conserved in myotubes established from diabetic subjects: evidence for primary defects in glucose transport and glycogen synthase activity. Diabetes 51:921-927

9. Gaster M, Beck-Nielsen H (2004) The reduced insulin mediated glucose oxidation in skeletal muscle from type 2 diabetic subjects may be of genetic origin - evidence from cultured myotubes. Biochim Biophys Acta 1690:85-91

10. Cusi K, Maezono K, Osman A et al (2000) Insulin resistance differentially affects the PI 3-kinase- and MAP kinase-mediated signaling in human muscle. J Clin Invest 105:311-320

11. Nikoulina SE, Ciaraldi TP, Carter L, Mudaliar S, Park KS, Henry RR (2001) Impaired muscle glycogen synthase in type 2 diabetes is associated with diminished phosphatidylinositol 3-kinase activation. J Clin Endocrinol Metab 86:4307-4314

12. Bouzakri K, Roques M, Gual P et al (2003) Reduced activation of phosphatidylinositol-3 kinase and increased serine 636 phosphorylation of insulin receptor substrate-1 in primary culture of skeletal muscle cells from patients with type 2 diabetes. Diabetes 52:1319-1325

13. Kelley DE, He J, Menshikova EV et al (2002) Dysfunction of mitochondria in human skeletal muscle in type 2 diabetes. Diabetes 51:2944-2950

14. Schrauwen-Hinderling VB, Kooi ME, Hesselink MK et al (2007) Impaired in vivo mitochondrial function but similar intramyocellular lipid content in patients with type 2 diabetes mellitus and BMI-matched control subjects. Diabetologia 50:113-120

15. Ritov VB, Menshikova EV, He J et al (2005) Deficiency of subsarcolemmal mitochondria in obesity and type 2 diabetes. Diabetes 54:8-14

16. Boushel R, Gnaiger E, Schjerling P et al (2007) Patients with type 2 diabetes have normal mitochondrial function in skeletal muscle. Diabetologia 50:790-796

17. Mogensen M, Sahlin K, Fernström M et al (2007) Mitochondrial respiration is decreased in skeletal muscle of patients with type 2 diabetes. Diabetes 56:1592-1599

18. Sreekumar R, Halvatsiotis P, Schimke JC et al (2002) Gene expression profile in skeletal muscle of type 2 diabetes and the effect of insulin treatment. Diabetes 51:1913-1920

19. Patti ME, Butte AJ, Crunkhorn S et al (2003) Coordinated reduction of genes of oxidative metabolism in humans with insulin resistance and diabetes: potential role of PGC1 and NRF. Proc Natl Acad Sci U S A 100:8466-8471
20. Mootha VK, Lindgren CM, Eriksson KF et al (2003) PGC-1alpharesponsive genes involved in oxidative phosphorylation are coordinately downregulated in human diabetes. Nat Genet 34:267-273

21. Skov V, Glintborg D, Knudsen S et al (2007) Reduced expression of nuclear-encoded genes involved in mitochondrial oxidative metabolism in skeletal muscle of insulin-resistant women with polycystic ovary syndrome. Diabetes 56:2349-2355

22. Petersen KF, Dufour S, Befroy D et al (2004) Impaired mitochondrial activity in the insulin-resistant offspring of patients with type 2 diabetes. N Engl J Med 350:664-671

23. Befroy DE, Petersen KF, Dufour S et al (2007) Impaired mitochondrial substrate oxidation in muscle of insulin-resistant offspring of type 2 diabetic patients. Diabetes 56:1376-1381

24. Petersen KF, Befroy D, Dufour S et al (2003) Mitochondrial dysfunction in the elderly: possible role in insulin resistance. Science 300:1140-1142

25. Toledo FG, Menshikova EV, Ritov VB et al (2007) Effects of physical activity and weight loss on skeletal muscle mitochondria and relationship with glucose control in type 2 diabetes. Diabetes 56:2142-2147

26. Gaster M, Kristensen SR, Beck-Nielsen H, Schroder HD (2001) A cellular model system of differentiated human myotubes. APMIS 109:735-744

27. Gaster M, Rustan AC, Aas V, Beck-Nielsen H (2004) Reduced lipid oxidation in skeletal muscle from type 2 diabetic subjects may be of genetic origin: evidence from cultured myotubes. Diabetes 53:542-548

28. Højlund K, Poulsen M, Staehr P, Brusgaard K, Beck-Nielsen H (2002) Effect of insulin on protein phosphatase 2A expression in muscle in type 2 diabetes. Eur J Clin Invest 32:918-923

29. Højlund K, Wildner-Christensen M, Eshøj O et al (2001) Reference intervals for glucose, beta-cell polypeptides, and counterregulatory factors during prolonged fasting. Am J Physiol 280:E50-E58

30. Irizarry RA, Hobbs B, Collin F et al (2003) Exploration, normalization, and summaries of high density oligonucleotide array probe level data. Biostatistics 4:249-264

31. Gentleman RC, Carey VJ, Bates DM et al (2004) Bioconductor: open software development for computational biology and bioinformatics. Genome Biol 5:R80

32. Højlund K, Wrzesinski K, Larsen PM et al (2003) Proteome analysis reveals phosphorylation of ATP synthase beta-subunit in human skeletal muscle and proteins with potential roles in type 2 diabetes. J Biol Chem 278:10436-10442

33. Karakelides H, Asmann YW, Bigelow ML et al (2007) Effect of insulin deprivation on muscle mitochondrial ATP production and gene transcript levels in type 1 diabetic subjects. Diabetes 56:2683-2689

34. Richardson DK, Kashyap S, Bajaj M et al (2005) Lipid infusion decreases the expression of nuclear encoded mitochondrial genes and increases the expression of extracellular matrix genes in human skeletal muscle. J Biol Chem 280:10290-10297

35. Wu X, Wang J, Cui X et al (2007) The effect of insulin on expression of genes and biochemical pathways in human skeletal muscle. Endocrine 31:5-17

36. Rome S, Clément K, Rabasa-Lhoret R et al (2003) Microarray profiling of human skeletal muscle reveals that insulin regulates $\sim 800$ genes during a hyperinsulinemic clamp. J Biol Chem 278:18063-18068

37. Stump CS, Short KR, Bigelow ML et al (2003) Effect of insulin on human skeletal muscle mitochondrial ATP production, protein synthesis, and mRNA transcripts. Proc Natl Acad Sci U S A 100:7996-8001

38. Petersen KF, Dufour S, Shulman GI (2005) Decreased insulinstimulated ATP synthesis and phosphate transport in muscle of 
insulin-resistant offspring of type 2 diabetic parents. PLoS Med 2: e233

39. Szendroedi J, Schmid AI, Chmelik M et al (2007) Muscle mitochondrial ATP synthesis and glucose transport/phosphorylation in type 2 diabetes. PLoS Med 4:e154

40. Tan Q, Brusgaard K, Kruse TA et al (2004) Correspondence analysis of microarray time-course data in case-control design. J Biomed Inform 37:358-365

41. Hansen L, Gaster M, Oakeley EJ et al (2004) Expression profiling of insulin action in human myotubes: induction of inflammatory and pro-angiogenic pathways in relationship with glycogen synthesis and type 2 diabetes. Biochem Biophys Res Commun 323:685-695
42. Ørtenblad N, Mogensen M, Petersen I et al (2005) Reduced insulin-mediated citrate synthase activity in cultured skeletal muscle cells from patients with type 2 diabetes: evidence for an intrinsic oxidative enzyme defect. Biochim Biophys Acta 1741:206-214

43. Nair KS, Bigelow ML, Asmann YW et al (2008) Asian Indians have enhanced skeletal muscle mitochondrial capacity to produce ATP in association with severe insulin resistance. Diabetes 57:1166-1175

44. Bonnard C, Durand A, Peyrol S et al (2008) Mitochondrial dysfunction results from oxidative stress in the skeletal muscle of diet-induced insulin-resistant mice. J Clin Invest 118:789-800 